\title{
The grand challenges in carbon capture, utilization, and storage
}

\author{
Berend Smit ${ }^{1,2}$ *, Ah-Hyung Alissa Park ${ }^{3,4}$ and Greeshma Gadikota ${ }^{3,4}$ \\ ${ }^{1}$ Department of Chemical and Biomolecular Engineering, University of California Berkeley, Berkeley, CA, USA \\ ${ }^{2}$ Energy Center and Laboratory of Molecular Simulation, Institut des Sciences et Ingénierie Chimiques, École Polytechnique Fédérale de Lausanne (EPFL), \\ Lausanne, Switzerland \\ ${ }^{3}$ Department of Earth and Environmental Engineering, Lenfest Center for Sustainable Energy, Columbia University, New York, NY, USA \\ ${ }^{4}$ Department of Chemical Engineering, Lenfest Center for Sustainable Energy, Columbia University, New York, NY, USA \\ *Correspondence: berend-smit@berkeley.edu \\ Edited and reviewed by: \\ Jennifer Wilcox, Stanford University, USA
}

Keywords: carbon capture, carbon dioxide utilization, carbon dioxide fixation, carbon dioxide separation, carbonate mineralization, enhanced oil recovery

\section{INTRODUCTION}

If we were in a global war against climate change, we would carry out largescale carbon capture, utilization, and storage (CCUS) (Smit et al., 2014). Some argue that if we fight the war against climate change via CCUS, this implies that we are promoting the continued use of fossil fuels instead of replacing fossil fuels by renewable energy such as solar and wind. At present, the contribution of fossil fuels in our energy supply is over $80 \%$, while the renewable is only $10 \%$ (International Energy Agency (IEA), 2013). Most, if not all, of the energy scenarios predict an increase in the share of the renewables, but in absolute numbers the fossil fuels will continue to provide most of our energy needs in the foreseeable future. This is simply because the growth in renewable energy will not be able to keep up with our increasing energy demand associated with a growing world population. In such a scenario, a war against climate change without CCUS implies that we have to dramatically reduce our current energy consumption, and hence, accept a dramatic reduction in GDP. Thus, the adaptation of large-scale CCUS might be inevitable to mitigate ever-increasing $\mathrm{CO}_{2}$ emissions with given population growth predictions.

At present, there are still very few signs of starting a war against climate change soon. The consequence is that we may significantly overshoot $\mathrm{CO}_{2}$ levels in the atmosphere before any serious action is taken. In such a scenario, it is very likely that we also need to deploy technologies that can achieve negative emissions (i.e., direct $\mathrm{CO}_{2}$ capture from air). In this scenario, the price of carbon will be so high that any technology that uses $\mathrm{CO}_{2}$ as a source of carbon will have such an economic advantage that $\mathrm{CO}_{2}$ will replace fossil fuels for those applications (e.g., plastics and soaps). Thus, $\mathrm{CO}_{2}$ utilization next to storage will be an integral component of carbon management.

\section{CARBON CAPTURE}

For carbon capture (Wilcox, 2012), it is important to distinguish between stationary sources (power plants, factories, etc.) and mobile sources (cars, airplanes, etc.) of $\mathrm{CO}_{2}$. At present, there are no practical solutions for on-board capture $\mathrm{CO}_{2}$ directly from mobile sources; therefore, we focus in the remainder on capturing $\mathrm{CO}_{2}$ from stationary sources.

\section{COAL-FIRED POWER PLANTS}

Removing $\mathrm{CO}_{2}$ from gases emitted from stationary sources can be done, using quite old technology. Most natural-gas contains more $\mathrm{CO}_{2}$ than is allowed to put in pipelines. Hence, gas companies use the amine scrubbing process developed by Bottoms (1930) to separate $\mathrm{CO}_{2}$ from methane. A very similar process can be used to remove $\mathrm{CO}_{2}$ from flue gas. There is very little doubt in the engineering community that this amine absorption technology can be scaled-up and implemented to capture flue gases. The problem, however, is that the regeneration of the amine solution and the subsequent compression of $\mathrm{CO}_{2}$ for transport and geological storage is very energy intensive. As a consequence, a power plant with carbon capture will not only be more expensive to build, but also will have reduction in efficiency as high as 35\% (Herzog et al., 1993). Research is therefore focused on increasing the efficiency of the absorption process and on finding alternatives (e.g., solid adsorption or membranes).

Building a new power plant in which carbon capture would be added from the very beginning would give more possibilities to optimize the efficiency of combined power generation and carbon capture. One such example is oxy-combustion in which coal is burned with pure oxygen, and $\mathrm{CO}_{2}$ is captured simply by condensing the water. In oxy-combustion, however, one needs to separate oxygen from the air, which is also an energy intensive separation. Other alternatives include, chemical looping, and integrated gasification combined cycle (IGCC), in which coal is converted into syngas, and the carbon capture process involves separation from $\mathrm{H}_{2}$.

\section{CARBON CAPTURE FROM DILUTE SOURCES}

Thermodynamics tells us that the lower the concentration of $\mathrm{CO}_{2}$, the more expensive it is to capture a ton of $\mathrm{CO}_{2}$ (House et al., 2011; Wilcox, 2012). Hence, most carbon capture effort has been initially focused on flue gas streams from coal-fired power plants, which contain about 15\% $\mathrm{CO}_{2}$. As coal was the cheapest source of fossil fuel for many years, such an objective made perfect sense. However, the scenarios did not forecast the availability of large amounts of cheap natural gas in recent years. Replacing coal-fired power plants by gas-fired power plants will significantly reduce $\mathrm{CO}_{2}$ emissions, but the scenario of burning all natural-gas reserves without CCS is only marginally less disastrous compared to burning all coal without CCS.

In the recent IPCC report (Stocker et al., 2013), the importance of negative 
emissions has been established. According to the most recent IPCC report, however, we are currently emitting more $\mathrm{CO}_{2}$ than predicted by the most pessimistic IPCC scenario. Therefore, it is more than likely that we will overshoot the target $\mathrm{CO}_{2}$ levels. In such a scenario, one may need technologies to activity mitigate the effects of climate change (Shepherd, 2009), which involves land management practices, accelerated weathering, albedo modification, etc., and also technologies to reduce carbon levels from the atmosphere (Keith, 2009; Lackner et al., 2012).

At present, one can achieve negative emissions by co-firing excess biomass in a coal-fired power plant and capturing the $\mathrm{CO}_{2}$ together with the $\mathrm{CO}_{2}$ from the coal. This Bio-energy CCS (BECCS) scheme has an environmental advantage that the flue gas of the biomass is cleaned using the existing infrastructure of the coal-fired power plant (Gough and Upham, 2011). However, there is not enough disposable biomass that this can be applied on a large-scale.

\section{UTILIZATION}

In the context of flue gases, $\mathrm{CO}_{2}$ is seen as a waste product. However, there are many applications, where $\mathrm{CO}_{2}$ is utilized or considered as a valuable commodity.

\section{ENHANCED OIL RECOVERY}

At present, $\mathrm{CO}_{2}$ is most valuable for enhanced oil recovery (EOR). In 2008, in the United States, about $80 \%$ of $\mathrm{CO}_{2}$ for EOR is obtained from natural resources and the rest is from anthropogenic sources such as coal gasification or gas processing (Advanced Resources International (ARI), 2010). The permanent storage of $\mathrm{CO}_{2}$ in depleted oil fields is definitely one of the attractive carbon storage options. The fact that there is a market for $\mathrm{CO}_{2}$ is an important incentive to develop more efficient carbon capture technologies, such that anthropogenic $\mathrm{CO}_{2}$ can compete with $\mathrm{CO}_{2}$ from natural reservoirs.

There are two practical issues. Firstly, the total amount of $\mathrm{CO}_{2}$ that can be used for EOR is much less than the total emissions of $\mathrm{CO}_{2}$, which implies that EOR can only be a partial solution. For example, $\mathrm{CO}_{2}$ used in EOR operations was limited to only 60 million tons (Advanced Resources International (ARI), 2010). Secondly, one may wonder whether EOR gives a net $\mathrm{CO}_{2}$ reduction. The argument is that because of EOR we produce more oil, and hence, further increase anthropogenic $\mathrm{CO}_{2}$ emissions. However, a better argument is to compare one barrel of oil produced with EOR compared to one barrel of oil that is produced without EOR. In this comparison, one barrel of oil with EOR gives a lower $\mathrm{CO}_{2}$ emission as a fraction of the $\mathrm{CO}_{2}$ used to recover the oil stays in the reservoir. However, here we did assume that the other barrel of oil does remain in the reservoir and that EOR does not increase the demand for oil.

\section{$\mathrm{CO}_{2}$ TO CHEMICALS}

If we look at the current chemical industry, about $7 \%$ of all oil is used as feedstock for carbon in products ranging from plastics to soaps. Replacing oil by a renewable feedstock is an important long-term challenge of the chemical industry. The viability of using $\mathrm{CO}_{2}$ as a chemical feedstock is considerably improved if the price of carbon is sufficiently high such that $\mathrm{CO}_{2}$ can replace oil. While the carbon-free energy sources required for $\mathrm{CO}_{2}$-to-chemical technologies (e.g., solar and wind) are still expensive for such $\mathrm{CO}_{2}$ utilization schemes, the research and development of those $\mathrm{CO}_{2}$ conversion pathways should be developed now to prepare for our rapidly changing future.

\section{$\mathrm{CO}_{2}$ TO FUELS}

The challenge with upgrading $\mathrm{CO}_{2}$ to a fuel is that it requires energy. As it does not make any sense to use fossil fuels for this process, we assume that we will use renewable energy. The first argument is, if we have renewable energies we should primarily use this for generating electricity. However, this leaves us with two problems: storage of energy and transportation fuels.

An important advantage of fossil fuels is their high energy density. Renewable energies such as wind or solar require largescale energy storage to ensure that electricity can be produced at time in which there is no wind or sun. Sometimes, this energy storage can be as simple as pumping water, but not all countries have this option. For example, Denmark has an excess of wind energy during the winter, but too little during summer. The idea is to use methanol to store the excess energy in the winter and use a conventional power plant with carbon capture in the summer. In this cycle, efficient conversion of $\mathrm{CO}_{2}$ into a fossil fuel like methanol is an essential step.

\section{INCORPORATING $\mathrm{CO}_{2}$ INTO CONSTRUCTION AND BUILDING MATERIALS}

The cement industry produces about $7 \%$ of $\mathrm{CO}_{2}$ emissions and is the second largest emitter of $\mathrm{CO}_{2}$ after coal-fired power plants (International Energy Agency Greenhouse Gas R\&D Programme (IEA-GHG), 2002). Replacing $10 \%$ of building materials with carbonate minerals is expected to reduce $\mathrm{CO}_{2}$ emissions by $1.6 \mathrm{Gt} /$ year, which is about $5 \%$ of the global $\mathrm{CO}_{2}$ emissions as of 2011 (Sridhar and Hill, 2011). However, it is important to determine the correct composition of carbonate minerals to be included in the concrete matrix to reduce issues related to mechanical strength of the materials.

\section{STORAGE}

Given the enormous amounts of $\mathrm{CO}_{2}$ we are emitting, it is difficult to imagine any form of carbon storage other than injecting into geological formations. Appropriate geological formations such as deep saline aquifers, depleted oil and gas fields, unmineable coal seams, and silicate formations (e.g., basalt) can accommodate up to $11,000 \mathrm{Gt} \mathrm{CO}_{2}$ (Dooley et al., 2006), which is much greater compared to the annual $\mathrm{CO}_{2}$ emissions, which are to the order of $30 \mathrm{Gt}$ of $\mathrm{CO}_{2}$ /year. In addition, from our experience with EOR we know how to transport and inject $\mathrm{CO}_{2}$ in geological formations. The challenge is, however, the scale. At present, only about $50 \mathrm{Mt} \mathrm{CO}_{2}$ has been stored today and $13 \mathrm{Mt} \mathrm{CO}_{2}$ /year is expected by 2016 given plans in place for additional projects (Levina et al., 2013).

However, the scientific challenge is to ensure that the $\mathrm{CO}_{2}$ remains safely in these storage sites for thousands of years. Development of technologies for monitoring, verification, and assessment (MVA) to entire that the $\mathrm{CO}_{2}$ remains trapped underground is essential. While the process of injecting $\mathrm{CO}_{2}$ is well understood, the cost of monitoring the fate of injected $\mathrm{CO}_{2}$ over many years may be too prohibitive unless, the cost of deploying MVA technologies is substantially reduced. In addition, key questions related to long-term safety such as induced seismicity and the potential for forming fractures need to be addressed, 
which constitute an important aspect of risk assessments of geologic storage.

Ideally, mineralizing $\mathrm{CO}_{2}$ into the form of a carbonate (e.g., limestone, magnesite) will reduce the amount of mobile $\mathrm{CO}_{2}$ that needs to be monitored. However, the kinetics of this natural process may be on the order of geological timescales. An active area of research is to enhance this mineralization process (Gadikota et al., 2014).

\section{OUTLOOK}

Given all the uncertainties, we argue that the first, and arguably, the most important challenge is to ensure that research is carried out on all aspects of CCUS. To reduce $\mathrm{CO}_{2}$ levels in the atmosphere, land management and bio-energy with CCS (BECCS) may be low-hanging fruit. We can further envision capture technologies that are highly optimized for point sources ranging from coal-fired and gasfired power plants to cement plants as well as direct air capture. The parasitic energy consumption should be lowered and the long-term recyclability of the $\mathrm{CO}_{2}$ capture medium should be achieved. Cuttingedge research in carbon storage and utilization (i) will improve our understanding of the long-term effects of large-scale injection of $\mathrm{CO}_{2}$ in geological formation, (ii) will enable us to develop alternatives for geological storage such as carbon mineralization, and (iii) will even allow for the development of the innovative chemistry to convert $\mathrm{CO}_{2}$ into synthetic fuels and chemicals.

\section{ACKNOWLEDGMENTS}

This publication is based on work supported by the National Science Foundation - Research Coordination Network on
Carbon Capture, Utilization and Storage (NSF RCN-CCUS).

\section{REFERENCES}

Advanced Resources International (ARI). (2010). U.S. Oil Production Potential from Accelerated Deployment of Carbon Capture and Storage. Available at: http://www.adv-res.com/pdf/v4ARI\% 20CCS-CO2-EOR\%20whitepaper\%20FINAL\% 204-2-10.pdf

Bottoms, R. R. (1930). Process for Separating Acidic Gases. U.S. Patent No. 1, 783, 901.

Dooley, J. J., Dahowski, R. T., Davidson, C. L., Wise, M. A., Gupta, N., Kim, S. H., et al. (2006). Carbon Dioxide Capture and Geologic Storage. Available at: http://www.epa.gov/air/caaac/coaltech/2007_02 _battelle.pdf

Gadikota, G., Matter, J., Kelemen, P. B., and Park A.-H. A. (2014). Chemical and morphological changes during olivine carbonation for $\mathrm{CO}_{2}$ storage in the presence of $\mathrm{NaCl}$ and $\mathrm{NaHCO}_{3}$. Phys. Chem. Chem. Phys. 16, 4679-4693. doi:10.1039/ c3cp54903h

Gough, C., and Upham, P. (2011). Biomass energy with carbon capture and storage (BECCS or BioCCS). Greenhouse Gases Sci. Technol. 1, 324-334. doi:10.1002/ghg.34

Herzog, H., Drake, E., Tester, J., and Rosenthal, R. (1993). A Research Needs Assessment for the Capture, Utilization, and Disposal of Carbon Dioxide from Fossil Fuel-Fired Power Plants. Cambridge, MA: Energy Laboratory, Massachusetts Institute of Technology.

House, K. Z., Baclig, A. C., Ranjan, M., van Nierop, E. A., Wilcox, J., and Herzog, H. J. (2011). Economic and energetic analysis of capturing $\mathrm{CO} 2$ from ambient air. Proc. Natl. Acad. Sci. U.S.A. 108, 20428-20433. doi:10.1073/pnas. 1012253108

International Energy Agency (IEA). (2013). Redrawing the Energy Climate Map. Available at: http://www. worldenergyoutlook.org/media/weowebsite/2013/ energyclimatemap/RedrawingEnergyClimateMap. pdf

International Energy Agency Greenhouse Gas R\&D Programme (IEA-GHG). (2002). Building the Cost Curves for $\mathrm{CO}_{2}$ Storage, Part 1: Sources of CO2, PH4/9 (Paris: International Energy Agency), 48.

Keith, D. W. (2009). Why capture $\mathrm{CO}_{2}$ from the atmosphere?. Science 325, 1654. doi:10.1126/science. 1175680
Lackner, K. S., Brennan, S., Matter, J. M., Park, A. H. A., Wright, A., and Van Der Zwaan, B. (2012). The urgency of the development of $\mathrm{CO}_{2}$ capture from ambient air. Proc. Natl. Acad. Sci. U.S.A. 109, 13156-13162. doi:10.1073/pnas.1108765109

Levina, E., Bennett, S., and Mccoy, S. (2013). Technology Roadmap Carbon Capture and Storage. Paris: International Energy Agency.

Shepherd, J. (ed.) (2009). Geoengineering the Climate: Science, Governance and Uncertainty. London: The Royal Society.

Smit, B., Reimer, J. R., Oldenburg, C. M., and Bourg, I. C. (2014). Introduction to Carbon Capture and Sequestration. London: Imperial College Press.

Sridhar, N., and Hill, D. (2011). Electrochemical Conversion of $\mathrm{CO} 2$ - Opportunities and Challenges, Research and Innovation - Position Paper 07-2011. Available at: http://www.dnv.com/binaries/dnvposition_paper_co2_utilization_tcm4-445820.pdf Stocker, T. F., Qin, D., Plattner, G.-K., Tignor, M., Allen, S. K., Boschung, J., et al. (2013). Climate Change 2013: The Physical Science Basis: Intergovernmental Panel on Climate Change. Working Group I Contribution to the Fifth Assessment Report. New York, NY: Cambridge University Press.

Wilcox, J. (2012). Carbon Capture. New York: Springer.

Conflict of Interest Statement: The authors declare that the research was conducted in the absence of any commercial or financial relationships that could be construed as a potential conflict of interest.

Received: 11 October 2014; accepted: 12 November 2014; published online: 26 November 2014.

Citation: Smit B, Park A-HA and Gadikota G (2014) The grand challenges in carbon capture, utilization, and storage. Front. Energy Res. 2:55. doi: 10.3389/fenrg.2014.00055

This article was submitted to Carbon Capture, Storage, and Utilization, a section of the journal Frontiers in Energy Research.

Copyright (c) 2014 Smit, Park and Gadikota. This is an open-access article distributed under the terms of the Creative Commons Attribution License (CC BY). The use, distribution or reproduction in other forums is permitted, provided the original author(s) or licensor are credited and that the original publication in this journal is cited, in accordance with accepted academic practice. No use, distribution or reproduction is permitted which does not comply with these terms. 